\title{
Reversible atrioventricular block after atrial septal defect closure with a Gore Cardioform Septal Occluder
}

\section{Bloqueo auriculoventricular reversible post cierre de comunicación interauricular con dispositivo Gore Cardioform Septal Occluder}

\author{
Marc Figueras-Coll ${ }^{*}$, Anna Sabaté-Rotés², Marc Roguera-Sopena ${ }^{3}$, and Pedro Betrián-Blasco ${ }^{1}$ \\ ${ }^{1}$ Department of Pediatric and Adult Congenital Interventional Cardiology; ${ }^{2}$ Department of Pediatric Cardiology. Vall d'Hebron Hospital; ${ }^{3}$ Department \\ of Pediatric Cardiology, Germans Tries i Pujol Hospital. Barcelona, Spain
}

Different degrees of atrioventricular (AV) block and other conduction disturbances have been previously reported after transcatheter closure of atrial septal defects (ASD), ${ }^{1,2}$ Direct mechanical compression against $\mathrm{AV}$ node tissue followed by an inflammatory response due to device friction or to foreign body reaction has been mentioned as possible causes. ${ }^{3-6}$ Although conduction disturbances may improve with time, progression has also been described. ${ }^{2,4,5}$

A 12-year-old boy with a normal basal electrocardiogram (ECG) was electively admitted for percutaneous ASD closure. Transesophageal echocardiography documented a $13 \mathrm{~mm} \times 10 \mathrm{~mm}$ ostium secundum ASD, with a deficient aortic rim, $8 \mathrm{~mm}$ tricuspid rim, and $40 \mathrm{~mm}$ total septal length. All other rims were suitable for percutaneous closure. A $25 \mathrm{~mm}$ Gore Cardioform Septal Occluder device $\left(\right.$ GCSO $^{\mathrm{TM}}$ ) (W.L: Gore and Associates, Flagstaff, Arizona) was initially chosen without balloon sizing (hospital policy with GCSO), but it moved easily during Minnesota maneuver. As a consequence, the device was removed, and a $30 \mathrm{~mm}$ GCSO was implanted uneventfully (Fig. 1). No arrhythmias or any degree of AV block were observed during or after the procedure. The following day, after a normal ECG
(Fig. 2A) and a normal echocardiographic assessment, the patient was discharged.

Forty-eight hours later, the patient was re-admitted due to fever. Blood test was negative for acute phase markers (C reactive protein $2.4 \mathrm{mg} / \mathrm{dL}$, and procalcitonin $0.06 \mathrm{ng} / \mathrm{mL}$ ) and hence, a non-infectious origin of the fever was suspected. An echocardiogram showed a well-positioned device without complications. An ECG, however, revealed a first-degree AV block together with intermittent runs of second-degree AV block Mobitz I (Figs. 2B and 2C). Suspecting that the conduction disturbance was secondary to inflammation caused by the GCSO device, intravenous steroid therapy with methylprednisolone was initiated. In the following $48 \mathrm{~h}$, the ECG showed a progressive normalization of PR interval (Fig. 2D), and a Holter recording performed the $4^{\text {th }}$ day evidenced persistent sinus rhythm. The patient was discharged home with a descending schedule of oral steroid dosing. Nickel allergy was ruled out with a skin patch test 2 months after steroids discontinuation and during follow-up no AV block recurrence was documented in multiple Holter recordings. Two years later the patient remains asymptomatic.
Correspondence:

*Marc Figueras-Coll

E-mail: mfiguerascoll @gmail.com
Available online: $30-01-2020$ Arch Cardiol Mex (Eng). 2020;90(1):90-92 www.archivoscardiologia.com
article under the CC BY-NC-ND 2604-7063 / @ 2019 Instituto Nacional de Cardiología Ignacio Chávez. Published by Permanyer. This is an open access article under the CC BY-NC-ND
license (http://creativecommons.org/licenses/by-nc-nd/4.0/). 


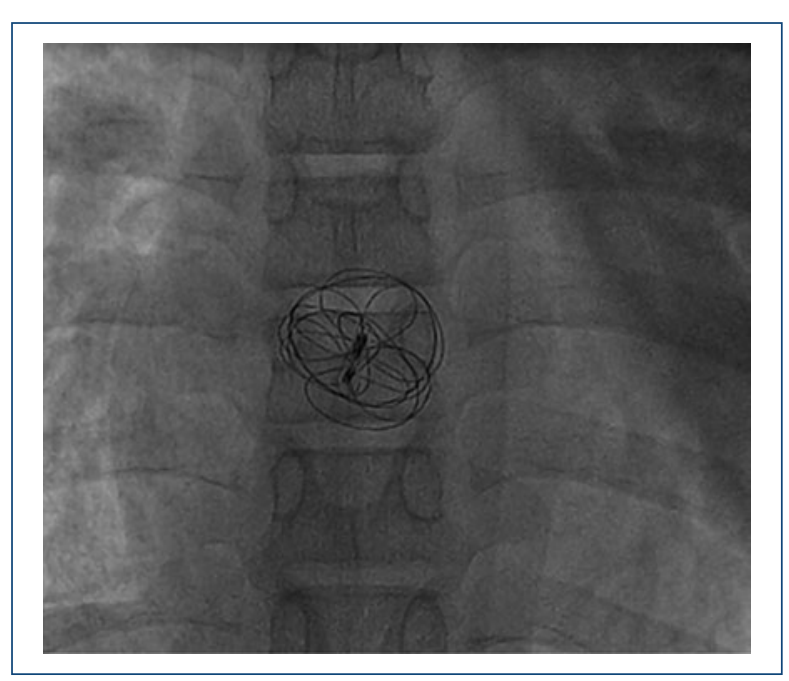

Figure 1. Fluoroscopy. Anteroposterior projection showing the GCSO device normopositioned.

Percutaneous closure of secundum ASD is considered safe and effective., ${ }^{1,7-9}$ However, during or after closure, conduction disturbances may be occasionally observed. ${ }^{2-4,6,7}$ The GCSO is a double-disc device with high compliance and flexibility, and it is made from nitinol covered by a polytetrafluoroethylene membrane.,10 Despite it is considered a "soft" device with low radial force and low compression stress on the tissue; a persistent GCSO-induced third-degree AV block has been reported. ${ }^{3}$

Although our patient was re-admitted due to fever, serial blood tests showed negative acute phase reactants and two blood cultures resulted negative. These lab data suggested more an inflammatory response than an infectious origin of the fever. Despite the fact that the exact mechanism of AV block after ASD closure remains unclear, a persistent mechanical compression, friction near $\mathrm{AV}$ node region, or a foreign body reaction, is all known to cause inflammation and edema that may damage AV node fibers and lead to different degrees of AV block. ${ }^{3-6}$

Use of large devices in young children, weight $<15 \mathrm{~kg}$, small tricuspid or posterior-inferior rim has been discussed as risk factors for AV block. It may also occur, however, in patients with adequate margins. ${ }^{2-4,6,9,11,12}$ In asymptomatic child's some authors recommend to post-pone the percutaneous ASD closure until preschool age (4 or 5 years of age) or weight $>15 \mathrm{~kg}^{3,9}$

The role of steroids for the treatment of $\mathrm{AV}$ conduction disturbances after percutaneous ASD closure remains debatable. ${ }^{6-8,12}$ In fact, whether the conduction improvement is due to an steroid effect or it is spontaneous remains to be clarified. Suda et al. described one case of third AV block among ten patients with a new-onset AV block after ASD closure with amplatzer septal occluder (ASO). Corticosteroids were given and rapid improvement was observed with recovery of sinus rhythm within 2 weeks. ${ }^{4}$ Similarly, Al Akhfash described a 7-year-old girl who $8 \mathrm{~h}$ after percutaneous closure of ASD with an ASO presented a second degree Mobitz I AV block and recovered sinus rhythm 4 days after being treated with prednisolone..$^{13}$ In our case, fever and inflammatory signs lead to trial with steroids with a good response. However, in other cases steroids may fail, or the initial improvement may be followed by conduction deterioration, requiring a surgical device extraction. Likewise, Al- Al-Anani et al. reported two cases and Amoozgar another one of AV block following percutaneous ASD closure where conservative treatment with steroids failed, and a surgical explantation was deemed necessary. ${ }^{2,5}$

Moreover, in the case herein described a negative skin patch test performed 2 months after steroid therapy excluded nickel allergy as a possible factor that could have damaged the AV node conduction through an allergic response to the nitinol device.

Of interest, in some patients there may be a spontaneous recovery that may be transient. This is the case described by Dittrich et al. of 36-month-old girl who presented a spontaneous improvement of a third-degree AV block after percutaneous ASD closure with a GCSO recovering sinus rhythm within 3 days. However, 11 months later deterioration of the AV conduction was observed when the patient suffered from undue fatigue associated with long-lasting episodes of complete heart block. A device explantation was then performed, but recovery was only partial since the patient was in sinus rhythm on day-time but she needed ventricular pacing while sleeping. ${ }^{3}$

Different degrees of AV block can be an early or a late complication after percutaneous ASD closure, even when using "soft" and flexible devices. ${ }^{3,8}$ Recently, Sato et al. reported a 7-year-old male patient who developed a severe AV block $7 \mathrm{~h}$ after percutaneous ASD closure with the "soft and flexible" Occlutech Figulla ${ }^{\circledR}$ Flex II ASD occluder, requiring surgical removal. ${ }^{8}$

The distinct cases of AV block reported highlight the importance of extending monitoring of cardiac rhythm from already before the percutaneous procedure through the long-term follow-up. ${ }^{6,7,13}$

Although complete heart block needing device explantation has been described, this is, to the best 


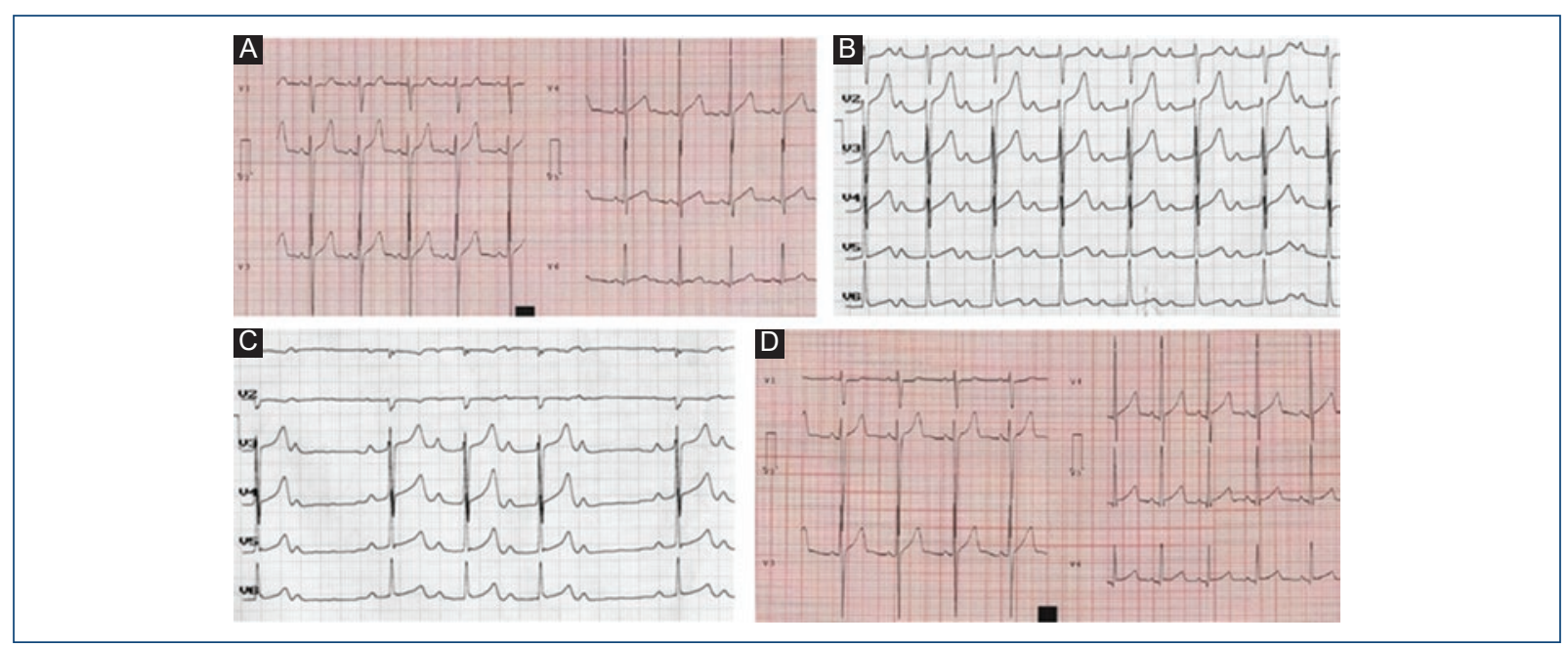

Figure 2. Electrocardiogram (ECG). A: Pre-procedure basal ECG showing sinus rhythm. B: Two days after Global Consortium for Sustainability Outcomes (GCSO) deployment showing first-degree AV block. C: Two days after GCSO deployment showing second-degree AV block, Mobitz I type. D: Four days after GCSO implantation showing sinus rhythm.

of our knowledge, the first reversible case of $\mathrm{AV}$ block after GCSO device implantation for ASD closure. In some occasions, early steroid therapy may prove effective by reducing $\mathrm{AV}$ node inflammation and restoring the sinus rhythm. In agreement with existing literature and to avoid pacemaker dependence, an early rather than a late removal of the device would seem reasonable whenever an inordinate and persistent pressure to the $\mathrm{AV}$ node region is suspected.

\section{Conflicts of interest}

None.

\section{Funding}

None.

\section{Ethical disclosures}

Protection of human and animal subjects. The authors declare that no experiments were performed on humans or animals for this study.

Confidentiality of data. The authors declare that they have followed the protocols of their work center on the publication of patient data.

Right to privacy and informed consent. The authors have obtained the written informed consent of the patients or subjects mentioned in the article. The corresponding author is in possession of this document.

\section{References}

1. Grohmann J, Wildberg C, Zartner P, Abu-Tair T, Tarusinov G, Kitzmüller $\mathrm{E}$, et al. Multicenter midterm follow-up results using the gore septal occluder for atrial septal defect closure in pediatric patients. Catheter Cardiovasc Interv. 2017;89:E226-E232.

2. Al-Anani SJ, Weber H, Hijazi ZM. Atrioventricular block after transcatheter ASD closure using the amplatzer septal occluder: risk factors and recommendations. Catheter Cardiovasc Interv. 2010:75:767-72.

3. Dittrich S, Sigler M, Priessmann H. Late complete atrioventricular block after closure of an atrial septal defect with a gore septal occluder (GSOTM). Catheter Cardiovasc Interv. 2016:87:945-50.

4. Suda K, Raboisson MJ, Piette E, Dahdah NS, Miró J. Reversible atrioventricular block associated with closure of atrial septal defects using the amplatzer device. J Am Coll Cardiol. 2004;43:1677-82.

5. Amoozgar $\mathrm{H}$, Ahmadipoor M, Amirghofran AA. Complete heart block following transcatheter closure of atrial septal defect due to growth of inflammatory tissue. Pediatr Cardiol. 2014;35:1301-3.

6. Chantepie A, Lefort B, Soulé N, Bonnefoy R, Labarthe F. Atrioventricular block after transcatheter atrial septal defect closure using the amplatzer septal occluder(囚). Arch Pediatr. 2013;20:1333-6.

7. Jalal Z, Hascoet S, Baruteau AE, Iriart X, Kreitmann B, Boudjemline $Y$, et al Long-term complications after transcatheter atrial septal defect closure: a review of the medical literature. Can J Cardiol. 2016;32:1315.e11-1.315E+21.

8. Sato J, Kato A, Takeda S, Nishikawa H. Case report: atrioventricular block after transcatheter atrial septal closure using the figulla® flex II ASD occluder. Catheter Cardiovasc Interv. 2019;93:E298-301.

9. Bartakian S, Fagan TE, Schaffer MS, Darst JR. Device closure of secundum atrial septal defects in children $<15 \mathrm{~kg}$ : complication rates and indications for referral. JACC Cardiovasc Interv. 2012;5:1178-84.

10. Abu-Tair T, Wiethoff CM, Kehr J, Kuroczynski W, Kampmann C. Transcatheter closure of atrial septal defects using the GORE(®) septal occluder in children less than $10 \mathrm{~kg}$ of body weight. Pediatr Cardiol. 2016;37:778-83.

11. Wang $Y$, Hua Y, Li L, Wang X, Qiao L, Shi X, et al. Risk factors and prognosis of atrioventricular block after atrial septum defect closure using the Amplatzer device. Pediatr Cardiol. 2014;35:550-5.

12. Rohit MK, Puri K, Vadivelu R. Reversible complete atrioventricular block after percutaneous ASD device closure in a child $<15 \mathrm{~kg}$. Indian Heart J. 2014;66:366-9.

13. Al Akhfash AA, Al-Mesned A, Fayadh MA. Amplatzer septal occluder and atrioventricular block: a case report and literature review. J Saudi Heart Assoc. 2013;25:91-4. 